\title{
Determination of deoxynivalenol in grain sorghum by chemiluminescence enzyme immunoassay
}

\author{
Zhenzhen $\mathrm{CHEN}^{1, \mathrm{a}}$, Lixin $\mathrm{ZHU}^{1, \mathrm{~b}}$, Renrong $\mathrm{LIU}^{1, \mathrm{c} *}$, Wei MENG ${ }^{1}, \mathrm{Na} \mathrm{HU}^{1}$, \\ Fanfan $\mathrm{YANG}^{1}$, Kaihong $\mathrm{LI}^{1}$, Yifan $\mathrm{LANG}^{1}$ \\ ${ }^{1}$ School of Life Science, Jiangxi Science \& Technology Normal University, Jiangxi, Nanchang, \\ 330013, China
}

*corresponding author, ${ }^{\mathrm{a} 827342314 @ q q . c o m,}{ }^{b}$ zhulixin007@163.com, ${ }^{\mathrm{C}}$ lilirenrong@hotmail.com

Keywords: Deoxynivalenol, Chemiluminescence enzyme immunoassay, grain sorghum

\begin{abstract}
A chemiluminescence enzyme-linked immunosorbent assay (CLEIA) with enhanced chemiluminescent was developed for the detection of deoxynivalenol (DON) in grain sorghum. Assay conditions, including concentrations of antibody and enzyme conjugate, $\mathrm{Na}^{+}(\mathrm{NaCl})$, organic solvent (methyl alcohol) and $\mathrm{pH}$ were investigated. The optimized CLEIA allowed the DON detection in a linear working range of $0.588-26.783 \mathrm{ng} \mathrm{mL}{ }^{-1}$ with the $\mathrm{IC}_{50}$ value of $3.968 \mathrm{ng}$ $\mathrm{mL}^{-1}$ and a limit of detection (LOD) of $0.311 \mathrm{ng} \mathrm{mL} \mathrm{m}^{-1}$. The CLEIA was one time more sensitive than the colorimetric ELISA by using the same antibody and HRP-conjugate. A series of spiked grain sorghum were detected by the method. The recovery rate ranged from $71.68 \%-96.56 \%$, and the coefficient variation (CV) ranged from $5.93 \%-13 \%$.
\end{abstract}

\section{Introduction}

Deoxynivalenol (DON) is produced by certain Fusarium fungus. It occurs more seriously in barley, wheat, corn, and oats but slightly in rye, sorghum and rice [1-3]. DON exhibited serious toxic effects to animals and human beings, such as feed refusal, weight loss, cardiotoxicity, teratogenicity, immunotoxicity and apoptosis in vitro without significant dose-effect relationship [1]. To protect human and animal safety, many countries established the limits of DON in cereals, the limit standard of DON in China is $1 \mathrm{mg} \mathrm{kg}^{-1}$ [4].

To control the contamination of DON in cereals, various analytical methods for the determination of DON in foods and feeds have been developed, which includes high performance liquid chromatography [5-7], and chromatography tandem mass spectrometry [8-9]. Although these methods are accurate and sensitive, they are time consuming and not suitable for rapid screening. The immunoassay assay was proved to be a good alternative method because of its simple, rapid, and sensitive characteristics with wide linear range. Then the immunoassay assay [10-14] for the detection of DON in food has been developed. This paper established luminol-hydrogen peroxide chemiluminescence system to detect DON in sorghum by indirect competitive chemiluminescent enzyme immunoassay.

\section{Materials and methods}

\section{Reagents}

Keyhole Limpet Hemocyani (KLH), DON and goat anti-mouse IgG-HRP was purchased from Sigama (St. Louis, USA). The anti-DON monoclonal antibody was obtained from our own laboratory. The chemiluminescence substrate solution was purchased from Helisence (Shanghai, China). Samples were purchased from a local market

\section{Buffers and Solutions}

0.01M phosphate-buffered solution (PBS, $\mathrm{pH} 7.4) .5 \%(\mathrm{w} / \mathrm{v})$ skimmed milk solution. PBST, 0.01M phosphate-buffered solution (PBS, pH7.4) with 0.05\% Tween-20 (v/v).

\section{Apparatus}

Luminoskan ascent (Thermo, USA), Wellwash versa (Thermo scientific), 96-well white polystyrene plates (Costar). Pipettes from Eppendorf Co, Ltd. were used in all experiments. 
Incubator.

\section{CLEIA procedure}

The micro-plates were coated with $120 \mu \mathrm{L}$ of DON-KLH solution per well diluted in $0.01 \mathrm{M}$ PBS for $2.5 \mathrm{~h}$ at $37^{\circ} \mathrm{C}$. The plates were washed with PBST 5 times then blocked with $5 \%$ skimmed milk $320 \mu \mathrm{L}$ was added to each well for $3.5 \mathrm{~h}$ at $37^{\circ} \mathrm{C}$. After the plates have been washed 4 times, $50 \mu \mathrm{L}$ antibody dilution solution and $50 \mu \mathrm{L}$ DON standard solution or sample solution was added. The plate was incubated at $37^{\circ} \mathrm{C}$ for $45 \mathrm{~min}$ then washed 5 times. Subsequently, $100 \mu \mathrm{L}$ 1:3000 (v/v) goat anti-mouse IgG-HRP dilution solution was added with incubation $45 \mathrm{~min}$ at $37^{\circ} \mathrm{C}$. At last, $100 \mu \mathrm{L}$ chemiluminescence substrate solution was added. The results were express in relative light units (RLU).

\section{CLEIA optimization}

The concentration of ionic strength, $\mathrm{pH}$, and organic solvent (methyl alcohol) were optimized. Competitive curves were created using 0.001M PBS solutions containing series concentrations of $\mathrm{Na}^{+}(\mathrm{NaCl})$, and $\mathrm{pH}$ values, methyl alcohol to evaluate the effects of ionic strength, $\mathrm{pH}$, and the solvent, respectively.

\section{Sample extraction and spiking}

The DON standard was added to each sorghum sample $(1 \mathrm{~g})$, Then $5 \mathrm{~mL}$ of acetonitrile- $\mathrm{H}_{2} \mathrm{O}$ (85: $15, \mathrm{v} / \mathrm{v}$ ) added to sample for extraction. Then the mixture was votered $30 \mathrm{~min}$ and centrifuged at $10000 \mathrm{rpm}$ for $15 \mathrm{~min} 4^{\circ} \mathrm{C}$. Then, the supernatant was dyed under $\mathrm{N}_{2}$ in $45^{\circ} \mathrm{C}$. After that the resident dissolved in super water.

\section{Results and Discussion}

\section{Optimization of the antigen concentration and antibody dilution}

Considered the RLU and, the optimization of antigen is $8 \mu \mathrm{g} \mathrm{L}^{-1}$. The antibody concentration was too low, led to the RLU was too small and all was blocked. So choose the dilution of antibody is from1:6000 to 1:48000. The CLEIA showed the highest RLU max/IC 50 when the antibody dilution was 1:6000.

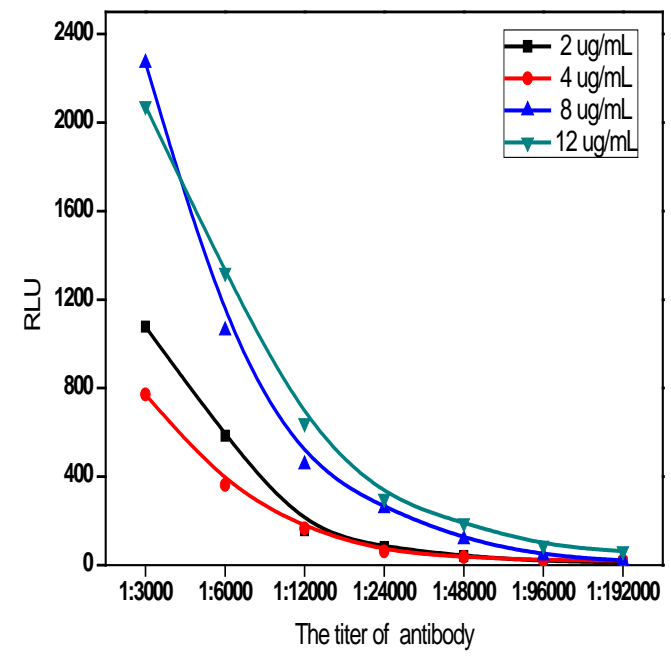

Fig.1. The concentration effect of DON-KLH on the DON immunoassay

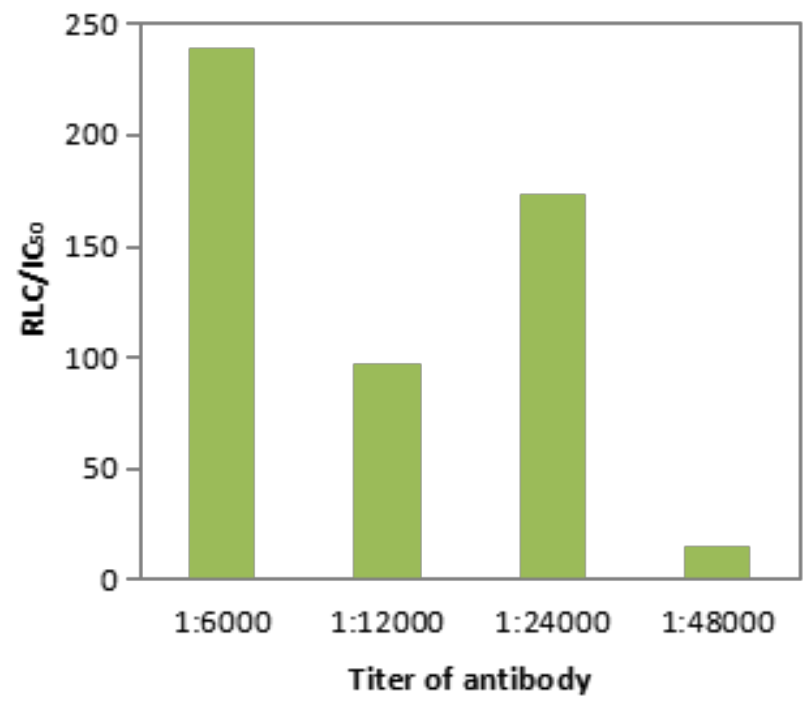

Fig.2 The effect of antibody dilution ratio on CLEIA

\section{Optimization of CLEIA}

The $\mathrm{RLU}_{\max } / \mathrm{IC}_{50}$ ratio was used as a parameter to judge the impact of factors. The $\mathrm{Na}^{+}$ concentration was evaluated from $0.4 \mathrm{~mol} \mathrm{~L}^{-1}$ to $1.6 \mathrm{~mol} \mathrm{~L}^{-1}$. The highest RLU max $/ \mathrm{IC}_{50}$ was obtained at $1.2 \mathrm{~mol} \mathrm{~L}-1 \mathrm{Na}^{+}$. The $\mathrm{pH}$ value was optimized from 4.4 to 8.4. At pH 6.4, the CLEIA showed the highest $\mathrm{RLU}$ max $/ \mathrm{IC}_{50}$ and the lowest LOD. The methyl alcohol concentration was evaluated from $0 \%$ to $20 \%$, affecting the CLEIA performance dramatically. The CLEIA showed the 
highest $\mathrm{RLU}_{\max } / \mathrm{IC}_{50}$ when the methyl alcohol concentration was $0 \%$. The result was showed in Table 1, the optimum parameters were1.2 $\mathrm{mol} \mathrm{L}^{-1} \mathrm{Na}^{+}$, pH6.4 and 0\% methyl alcohol for CLEIA.

Table 1. Effect of ionic strength, $\mathrm{pH}$ and organic solvent value on

CLEIA

\begin{tabular}{|c|c|c|c|c|}
\hline & & CLEIA & & \\
\hline & & $\mathrm{IC}_{50}\left(\mu \mathrm{gL}^{-1}\right)$ & $\mathrm{RLU}_{\max } / \mathrm{IC}_{50}$ & $\mathrm{R}^{2}$ \\
\hline \multirow{4}{*}{$\mathrm{Na}^{+}\left(\mathrm{mol} \mathrm{L}^{-1}\right)$} & 0.4 & 4.77 & 93 & 0.983 \\
\hline & 0.8 & 4.69 & 103 & 0.992 \\
\hline & 1.2 & 2.54 & 181 & 0.990 \\
\hline & 1.6 & 5.30 & 141 & 0.991 \\
\hline \multirow[t]{4}{*}{$\mathrm{pH}$ value } & 5.4 & 3.39 & 223 & 0.967 \\
\hline & 6.4 & 1.28 & 508 & 0.974 \\
\hline & 7.4 & 2.01 & 380 & 0.971 \\
\hline & 8.4 & 4.46 & 153 & 0.992 \\
\hline \multirow{5}{*}{$\begin{array}{l}\text { methyl } \\
\text { alcohol(\%,V/V) }\end{array}$} & $0 \%$ & 4.70 & 879 & 0.984 \\
\hline & $5 \%$ & 6.85 & 588 & 0.985 \\
\hline & $10 \%$ & 8.25 & 419 & 0.991 \\
\hline & $15 \%$ & 8.36 & 409 & 0.981 \\
\hline & $20 \%$ & 12.34 & 239 & 0.991 \\
\hline
\end{tabular}

\section{Establishment of the Standard Curve}

The CLEIA was established under optimal conditions.Fig.3 shows the standard curve for DON immunoassay based on CLEIA. From the calibration curves, we can calculate the $\mathrm{IC}_{50}$ was 3.968 $\mathrm{ng} \mathrm{mL}^{-1}$ and $\mathrm{IC}_{10}$ was $0.311 \mathrm{ng} \mathrm{mL}^{-1}$. The linear working range determined was $0.588-26.783 \mathrm{ng}$ $\mathrm{mL}^{-1}$.

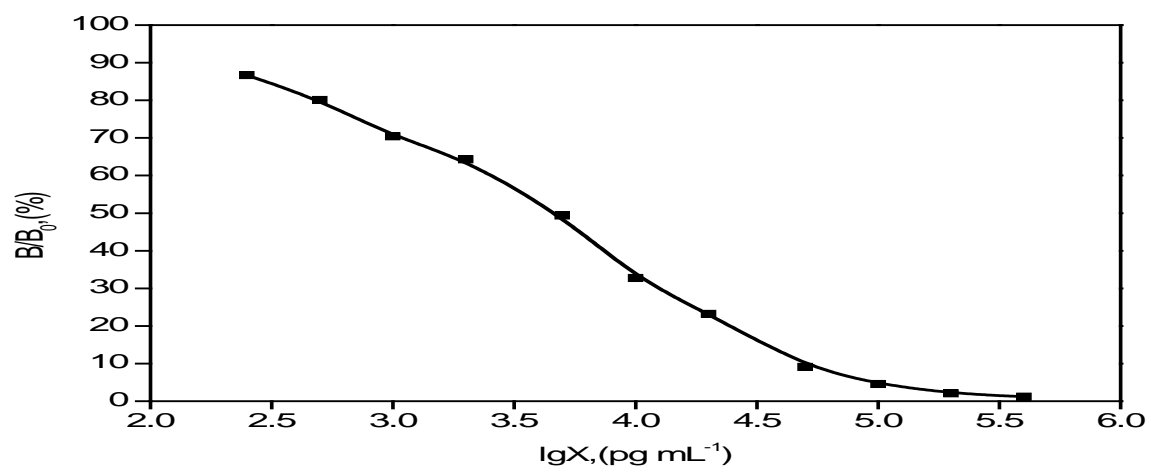

Fig. 3 Standard curve of CLEIA procedure for DON

\section{Recovery test of Spiked Samples}

Sorghum samples were spiked with DON at concentration of 120,400 and $800 \mathrm{ng} \mathrm{g}^{-1}$ respectively, and then they were analyzed by using the optimized CLEIA. Mean recovery values ranged from 71.68\%-96.56\% with coefficient variation (CV) less than13 \%. (Table. 2)

Table 2 The recovery of determination of DON in sorghum

\begin{tabular}{|c|c|c|c|c|}
\hline \multirow{3}{*}{ Sample } & & Spiked level $\left(\mathrm{ng} \mathrm{g}^{-1}\right)$ & & CV(\%) \\
\hline \multirow{3}{*}{ Sorghum } & Analyte & & Mean recovery (\%) & \\
\cline { 3 - 5 } & & 120 & 71.68 & 13 \\
\cline { 2 - 5 } & & 400 & 96.56 & 7.88 \\
\cline { 2 - 5 } & & 800 & 83.64 & 5.93 \\
\hline
\end{tabular}

\section{Conclusions}

In this study, CLEIA method for the detection of DON in sorghum was established. It was performed with wide linear range and lower limit of detection. This developed CLEIA method 
could be a suitable tool for rapid screening of DON in sorghum samples.

\section{Acknowledgements}

This work was financially supported by grants from National Natural Science Foundation of China (No.81360429) and Natural Science Foundation of Jiangxi Province (No. 20122BAB214006, 20114BAB205039, KJLD14067).

\section{References}

[1] Xinghua Huo, Baoyu Zhao, XuePan Wan, et al. the development of deoxynivalenol toxicity research [J].Toxicol, 2008, 22(2) 151-154.

[2] XiaoMing Zhu, Ailian Yu. The development of deoxynivalenol toxicity research [J].Medical.2010,16(9):1294-1296.

[3] Ying Cui. Mechanism of apoptosis induced by deoxynivalenol. 2012

[4] National Criterion of China, Maximum levels of mycotoxins in foods, GB/T 2761-2011

[5] M. Raters, R. Matissek. Sensitive method for determination of DON in cocoa by means of HPLC-techniques [J]. Mycotoxin Research, 2007, 23 (4) 185-190.

[6] Rouhollah Karami-Osboo, Mehdi Maham, Ramin Miri et al. Evaluation of dispersive liquid-liquid microextraction-HPLC-UV for determination of Deoxynivalenol(DON) in Wheat Flour Food [J]. Anal Methods (2013) 6 176-180.

[7] Yingpeng Luo, Zhengxing Chen, Ren wang et al. Determination of Deoxynivalenol in Wheat Grains by HPLC Using Solid-Phase Extraction Cleanup Column [J], Food Science. 2015, 36, (20) 222-225.

[8] Ran Ran, Wei Zhang, Bo Cui et al. A simple and rapid method for the determination of deoxynivalenol in human cells by UPLC-TOF-MS [J], Analytical Methods, 2013 (5) 5637-5643.

[9] Marita Beyer, Sven Dänicke, Dirk Rohweder et al, Determination of deoxynivalenol-sulfonate (DONS) in cereals by hydrophilic interaction chromatography coupled to tandem mass spectrometry [J]. Mycotox Res, 2010 (26) 109-117.

[10]L. Schneider, H. Pichler, R. Krska. An enzyme linked immunoassay for the determination of deoxynivalenol in wheat based on chicken egg yolk antibodies [J]. Fresenius $\mathrm{J}$ Anal Chem, 2000(367) 98-100.

[11] Stefania Valenzano, Vincenzo Lippolis, Michelangelo Pascale et al. Determination of Deoxynivalenol in Wheat Bran and Whole-Wheat Flour by Fluorescence Polarization Immunoassay [J]. Food Anal Methods, 2014 (7) 806-813

[12]Qirong Xiong, Yong Jin, Shige Xing, Development of an immuno- chromatographic strip test for the rapid detection of deoxynivalenol in wheat and maize, Food science and Technology [J]. 201439 (02) 292-296.

[13] Jinshen Chu, Yang Xu, Qinghua He, et al. Chemiluminescence enzyme immunoassay for the determination of deoxynivalenol in corn.science and technology of food industry [J]. 2011, 32 (09) 407-410.

[14] Yanshen Li, Gongzhen Liu, Xuejun Fu et al. High-Sensitive Chemiluminescent ELISA Method Investigationfor the Determination of Deoxynivalenol in Rice [J].Food Anal. Methods, 2015 (8) 656-660. 